\title{
Mechanical properties examined by nanoindentation for selected phases relevant to the development of monolithic uranium-molybdenum metallic fuels
}

\author{
Ryan Newell ${ }^{1}$, Youngjoo Park ${ }^{1}$, Abhishek Mehta ${ }^{1}$, Dennis Keiser Jr. ${ }^{2}$, Yongho Sohn ${ }^{1, *}$ \\ ${ }^{1}$ Department of Materials Science and Engineering \\ University of Central Florida, Orlando, FL, 32826, USA \\ ${ }^{2}$ Nuclear Fuels and Materials Division \\ Idaho National Laboratory, Idaho Falls, ID, 83402, USA
}

* Corresponding author

Department of Materials Science and Engineering

University of Central Florida, 12760 Pegasus Drive, Orlando, FL 32816

Voice: (407) 882-1181; Email: Yongho.Sohn@ucf.edu 


\begin{abstract}
Nanomechanical properties, specifically the reduced modulus and hardness of several intermetallic and solid solution phases are reported to assist the development of the U-10 wt.\% Mo (U-10Mo) monolithic fuel system for research and test reactors. Findings from this study and reported values of mechanical properties provide data critical for understanding and predicting the structural behavior of the fuel system during fabrication and irradiation. The phases examined are products of interdiffusion and reaction between (1) the AA6061 cladding and the $\mathrm{Zr}$ diffusion barrier, namely $(\mathrm{Al}, \mathrm{Si})_{3} \mathrm{Zr}$ and $\mathrm{Al}_{3} \mathrm{Zr}$, (2) the $\mathrm{U}-10 \mathrm{Mo}$ fuel and the $\mathrm{Zr}$ diffusion barrier, namely $\mathrm{UZr}_{2}, \mathrm{Mo}_{2} \mathrm{Zr}$, and $\alpha-\mathrm{U}$, and (3) the $\mathrm{U}$ (or $\mathrm{U}-10 \mathrm{Mo}$ ) and Mo, namely a mixture gradient of $\alpha$ - and $\gamma$-phases. The UC inclusions observed within the fuel alloy were also examined. Only phases present in thick or continuous microstructure on cross-sectioned fuel plates and diffusion couples were investigated for reduced modulus and hardness. Concentrationdependence of room-temperature reduced modulus in U solid solution with 0 to $10 \mathrm{wt}$ \% Mo was semi-quantitatively modeled based on mixture of $\alpha$ - and $\gamma$-phases and solid solutioning within the $\gamma$-phase.
\end{abstract}




\section{Introduction}

The Material Management and Minimization Program Reactor Conversion (M3 or MMMRC) program aims to minimize the use of highly enriched uranium (HEU) by utilizing low enriched uranium (LEU) as the fuel alloy in high-performance research test reactors [1]. This transition calls for the application of high-density uranium fuels with concentrations of fissile U235 below $20 \%$. The fuel alloys have been tailored to promote efficiency and safety, capitalizing on the relatively stable behavior of $\gamma-\mathrm{U}$ in comparison to $\alpha-\mathrm{U}$. The orthorhombic $\alpha$-phase is defined by anisotropy in radiative swelling and elastic behavior [2], while the body-centered cubic $\gamma$-phase has demonstrated predictable and preferred isotropic behavior [3]. In monolithic fuel plates, uranium has been alloyed with varying molybdenum content to promote the $\gamma$-phase stability. With increasing molybdenum concentration, the $\gamma$-phase stability in the fuel alloy increases, but at the expense of fissile uranium density [4]. The concentration for the optimum behavior with respect to fissile uranium density, $\gamma$-phase stability, and irradiation performance has been identified as 10 weight percent molybdenum (U-10Mo) [5] for the monolithic fuel system.

For the fabrication of the monolithic fuel system, the U-10Mo fuel alloy is first cast and then safely enclosed for use without any undesirable interaction with the cladding surrounding it [6]. To realize these goals, the foil undergoes a series of rolling and hot isostatic press (HIP) operations, resulting in an AA6061 cladding enclosing the U-10Mo fuel meat with a Zr diffusion barrier between the fuel and cladding [7,8,9]. Figure 1 shows a cross-section of a typical fuel plate sample after HIP processing [10].

The interdiffusion and reaction between the AA6061 cladding, $\mathrm{Zr}$ diffusion barrier, and U-10Mo fuel have been investigated for constituent phases, growth kinetics and microstructural 
development [6,9-13]. The phases identified include several intermetallic compounds and solid solutions that have not been extensively investigated for their mechanical properties. Knowledge of mechanical properties would be critical to optimize/model fuel fabrication and predict/assess irradiation performance. The aim of this study is to investigate, by nanoindentation, the mechanical properties of phases that have been observed in the monolithic fuel plates, particularly those developed as a result of interdiffusion and reaction between the fuel alloy, diffusion barrier, and cladding alloy.

The primary regions of interest are the interface between the fuel alloy and diffusion barrier (U-10Mo/Zr), interface between the diffusion barrier and cladding (Zr/AA6061), and the bulk U-10Mo fuel as a function of Mo content. In previous study, interdiffusion and reaction between the fuel alloy and $\mathrm{Zr}$ diffusion barrier have been investigated [9,12], and the phases reported to develop include $\mathrm{Mo}_{2} \mathrm{Zr}, \mathrm{UZr}_{2}$, and Mo-depleted $\alpha$-U. The reaction between the $\mathrm{Zr}$ diffusion barrier and the AA6061 cladding has been also documented [10], and the main product of this interaction has been identified as $(\mathrm{Al}, \mathrm{Si})_{3} \mathrm{Zr}$. In this study, nanoindentation was carried out using various fuel plate samples $[9,10]$ to examine the mechanical behavior of these phases. Additional diffusion couple experiments were carried out produce "thick" layers (e.g., greater than tens of micrometers and up to hundreds of micrometers) of some intermetallic phases, when the intermetallic layer developed on fuel plate samples was too thin for reliable nanoindentation.

\section{Experimental Details}

For intermetallic phases and solid solutions examined in this study, quasi-static nanoindentation was carried out using a Hysitron ${ }^{\text {TM }}$ TI Premier indenter with a Berkovich tip. 
The resulting unloading curves were analyzed for elastic modulus, $\mathrm{E}_{\mathrm{r}}$, and hardness, $\mathrm{H}$, using Oliver and Pharr's method [14,15]. Young's Modulus of the sample can be estimated from the reduced modulus provided Young's modulus of the indenter tip, Poisson's Ratio of the indenter tip, and Poisson's Ratio of the sample are known, according to the relationship [14,15]:

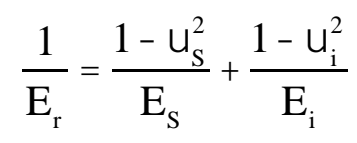

where $\mathrm{E}_{\mathrm{s}}, v_{\mathrm{s}}, \mathrm{E}_{\mathrm{i}}$, and $v_{\mathrm{i}}$ refer to, respectively, Young's Modulus of the sample, Poisson's ratio of the sample, Young's modulus of the indenter tip, and Poisson's ratio of the indenter. For a diamond indenter tip employed in this study, $\mathrm{E}_{\mathrm{i}}$ and $v_{\mathrm{i}}$ are 1,140 GPa and 0.07 , respectively. To achieve the target depths while maintaining consistent loading conditions, an $8 \mathrm{mN}$ peak load was applied with a 3 second hold at peak load throughout this investigation.

In this study, hot isostatically pressed (HIP) monolithic fuel plate samples $[7,10,13,16,17]$ and solid-to-solid diffusion couple samples $[9,11,12,18]$ were examined via nanoindentation as listed in Table I. For the fuel plate samples, the U-10Mo fuel foil was first arc-cast, after which the $\mathrm{Zr}$ diffusion barrier was co-rolled several times until the desired thickness was reached. Following co-rolling, the Zr-laminated U-10Mo sample was enclosed in a two-piece AA6061 casing, and bonded via HIP. The fabrication parameters for monolithic HIP plates have been described in detail elsewhere $[7,10,13,16,17]$. The sample utilized in this study was denoted as “HIP Plate 56-180," and hot isostatically pressed at $560^{\circ} \mathrm{C}$ for 180 minutes although typical HIP is carried out at $560^{\circ} \mathrm{C}$ for 90 minutes [10]. Any phases that form due to interdiffusion and reaction would be thicker in samples HIP'ed for 180 minutes, and would yield more reliable nanoindentation results. 
In the HIP'ed fuel plate sample, several phases of interest were not observed in thick and continuous quantities. These phases were intentionally grown on a larger scale through diffusion couple experiments as listed in Table I. For diffusion couples, U-10Mo vs. $\mathrm{Zr}$ annealed at $800^{\circ} \mathrm{C}$ for 480 hours and $\mathrm{U}$ vs. Mo annealed at $1000^{\circ} \mathrm{C}$ for 24 hours, development of phase constituents, interdiffusion and growth kinetics have been previously reported [18]. Three additional diffusion couples, $\mathrm{U}$ vs. $\mathrm{U}-10 \mathrm{Mo}, \mathrm{Al}$ vs. $\mathrm{Zr}$, and $\mathrm{U}$ vs. $\mathrm{Zr}$, were assembled and annealed in this study as reported in Table I. Diffusion couples were fabricated by placing the two target metals in steel jigs, and enclosing them within a quartz capsule. The quartz capsule was then flushed three times each with ultra-high purity $\mathrm{Ar}$ and $\mathrm{H}_{2}$ gas, to remove any traces of oxygen. The quartz capsules were then evacuated to the vacuum of $2.0 \times 10^{-5}$ torr or better, and sealed, to be annealed at a predetermined temperature and time. Diffusion couples were water-quenched to retain the hightemperature phase constituents and microstructure. Details of experimental procedure related to diffusion couple assembly have been documented in detail previously $[9,11,12,18]$.

Arrays of indents were analyzed to provide a larger number of data points on phases with sufficient thickness, and often, simultaneous testing of several different materials or phases across the interface. Throughout the investigation, each indentation was sufficiently placed apart, e.g., 10 times the depth of the indentation.

To better understand the changes in mechanical behavior for U-Mo solid solution upon water-quenching of diffusion couples, the concentration profiles were collected using X-ray energy dispersive spectroscopy (XEDS) for the U vs. U-10Mo couples, and electron probe microanalysis (EPMA) for the U vs. Mo couples [18]. Several TEM samples were prepared via in-situ lift out (INLO) method using FEI ${ }^{\mathrm{TM}}$ TEM 200-FIB. Microstructural examination was performed using FEI/Tecnai ${ }^{\mathrm{TM}}$ F30 TEM operating at an accelerating voltage of $300 \mathrm{KeV}$. XEDS 
and selected area electron diffraction (SAED) were employed, respectively, to quantify the composition of each phase, and identify its crystallographic structure.

\section{Results and Discussion}

Figure 2 presents microstructure of various phases observed in HIP fuel plate and diffusion couples. For better statistical averaging of mechanical properties, bulk phases were subjected to large numbers of indents. However, as reported in Table II, only a limited number of indents was possible on the phases that were present as precipitates or a discontinuous layer. Thus, for $\mathrm{UC}, \mathrm{UZr}_{2}$, and $\mathrm{Mo}_{2} \mathrm{Zr}$ phases, only indents completely and clearly within the phase were included for analysis. Table II reports hardness and reduced modulus determined using Oliver and Pharr's method [14,15], along with estimated Young's modulus based on Eq. [1]. In Table II, Poisson's ratio for each of the phase, required for the estimation of Young's modulus, was taken from various references [19-23], while an assumed value of 0.3 was employed for $\mathrm{UZr}_{2}$ and $\mathrm{Mo}_{2} \mathrm{Zr}$ due to lack of data in literature.

The $(\mathrm{Al}, \mathrm{Si})_{3} \mathrm{Zr}$ phase developed in the monolithic fuel plate at the diffusion barriercladding interface, and had a hardness of $11.4 \pm 0.85 \mathrm{GPa}$ and a reduced modulus of $173.3 \pm 4.7$ GPa, based on indentations shown in Figure 3. The (Al,Si $)_{3} \mathrm{Zr}$ phase in HIP'ed plates has been crystallographically identified previously by Perez et al. [6] as tI16. While the hardness may be overestimated due to the size effect of the indent, the size of the indent was limited by the width of the phase. Indents were examined carefully so that the entire indent is contained within the phase, and thus the constant loading was maintained. 
Since the $(\mathrm{Al}, \mathrm{Si})_{3} \mathrm{Zr}$ phase in the HIP plate sample was relatively thin $(<3 \mu \mathrm{m}), \mathrm{Al}$ vs. $\mathrm{Zr}$ diffusion couple was examined, where the $\mathrm{Al}_{3} \mathrm{Zr}$ phase was developed to a thickness of approximately $77 \mu \mathrm{m}$ with an average composition of 75.5 at.\% $\mathrm{Al}$ according to XEDS. According to $\mathrm{Fu}$ et al. [24], this phase may exhibit a metastable $\mathrm{L}_{2}$ crystal structure, or a $\mathrm{D} 0_{23}$ crystal structure, which is described as the stable structure [25-27]. The diffusion couple investigated in this study was annealed at $425^{\circ} \mathrm{C}$, and therefore would produce the stable $\mathrm{D}_{23}$ crystal structure. A hardness of $11.2 \pm 1.28 \mathrm{GPa}$ and a reduced modulus of $206.0 \pm 15.4$ were obtained for the $\mathrm{Al}_{3} \mathrm{Zr}$ phase based on indentations shown in Figure 4. The estimated Young's modulus is close to that determined by first principle calculations [20] as reported in Table II. Due to inhomogeneous microstructural development, results obtained from the $\mathrm{Al}_{2} \mathrm{Zr}$ phase could not be analyzed with any certainty. Both phases are not only potentially relevant in the cladding-diffusion barrier interaction in monolithic fuel plates, but also in lightweight structural materials $[19,28]$.

A complex interaction occurs between the U-10Mo fuel and $\mathrm{Zr}$ diffusion barrier. The primary constituents, according to HIP plate characterization, include $\mathrm{UZr}_{2}$ and $\mathrm{Mo}_{2} \mathrm{Zr}[6,11]$. $\mathrm{The}_{\mathrm{UZ}}$ phase developed adjacent to the $\mathrm{Zr}$ diffusion barrier although in sizes and quantities too small for reliable and statistically confident indentation results. $\mathrm{The}_{\mathrm{UZ}} \mathrm{Z}_{2}$ phase has been described as an equilibrium phase at $580^{\circ} \mathrm{C}$ [29] and consequently, the $\mathrm{UZr}_{2}$ phase was grown in a diffusion couple as reported in Table I and shown in Figure 2(c). The crystal structure of $\mathrm{UZr}_{2}$ is a $\mathrm{C} 32$ type structure, following the $\mathrm{AlB}_{2}$ prototype [30,31]. Based on indentation presented in Figure 5, a hardness of $5.4 \pm 0.20 \mathrm{GPa}$ and a reduced modulus of $126.7 \pm 1.9$ were obtained for the $\mathrm{UZr}_{2}$ phase. 
Due to the interdiffusion and reaction between U-10Mo fuel and $\mathrm{Zr}$ diffusion barrier, $\mathrm{Mo}_{2} \mathrm{Zr}$ and $\alpha-\mathrm{U}$ have been observed to develop. The $\mathrm{Mo}_{2} \mathrm{Zr}$ phase was fabricated in larger amount in diffusion couples in order to study microstructural evolution and kinetics in the U-Mo$\mathrm{Zr}$ system [12]. Even in diffusion couples, $\mathrm{Mo}_{2} \mathrm{Zr}$ phase did not develop into a continuous layer, but the indentation was carefully carried out to assess the properties as shown by red circles in Figure 6. $\mathrm{Mo}_{2} \mathrm{Zr}$, a C15 Laves phase [32], possessed a hardness of 13.0 $\pm 1.11 \mathrm{GPa}$ and reduced modulus of $157.7 \pm 9.5 \mathrm{GPa}$ as reported in Table II.

With the formation of $\mathrm{Mo}_{2} \mathrm{Zr}$, the Mo-depleted $\gamma$-phase transforms to $\alpha$ - $\mathrm{U}$ with negligible Mo solubility in the fuel plate samples. In this study, indentation results for the $\alpha$-U were also obtained from the $\mathrm{U}$ vs. $\mathrm{Zr}$ annealed at $580^{\circ} \mathrm{C}$ for 360 hours, sufficiently away from any interdiffusion and reaction, at the terminal end of the $U$ metal. Hardness and reduced modulus of $\alpha$-U were obtained as $4.7 \pm 0.1 \mathrm{GPa}$ and $169.0 \pm 3.2 \mathrm{GPa}$, respectively, as reported in Table II. Results reported were carefully gathered to avoid any influence of inclusions (e.g., oxide, carbides, etc.) occasionally found in pure U metals. The Young's modulus estimated using Eq. [1] for $\alpha$-U was lower than that reported in literature [33] by approximately $10 \%$. The discrepancy may be attributed in part to high anisotropy of the orthorhombic $\alpha$ phase, since small scale indentations are sensitive to local differences in crystallographic direction [34]. Residual stress present in the water-quenched diffusion couples [35] in part may also attributed to the discrepancy.

From the diffusion couples, U vs. Mo [18] and U vs. U-10Mo, indentation testing was carried out as a function of Mo concentration. The Mo content was determined using EPMA for the U vs. Mo couple [18] and XEDS for the U vs. U-10Mo diffusion couple. Concentrationdependent Young's modulus and hardness obtained from the U vs. Mo diffusion couple through 
nanoindentation are presented in Figure 7. For U vs. U-10Mo diffusion couples, results from nanoindentation on were remarkably identical both in magnitude and trend. The properties of UMo alloys have been the subject of several investigations [22,36,37], and their results are also presented in Figure 7 for comparison. The hardness values from literature presented in Figure 7 have been converted from VHN to GPa by multiplying the reported values by 0.00987 [38]. The U-Mo solid solution in the diffusion couple exhibited Young's modulus in good agreement with those observed by tensile testing at several concentrations, including $97.0 \mathrm{GPa}$ at $10 \mathrm{wt} . \%$ Mo in the diffusion couple compared to $86.9 \mathrm{GPa}$ at $10 \mathrm{wt} . \%$ Mo reported by Waldron et al. [22]. Young's modulus decreased with an increase in Mo content from 0 to approximately 6 wt.\%, and then increased with a further increase in Mo content as shown in Figure 7(a). The initial decrease in modulus can be attributed to the stabilization of softer $\gamma$-phase as the amount of $\gamma$-phase would increase as a function of Mo content upon cooling. Within the stabilized $\gamma$-phase having Mo content higher than $6 \mathrm{wt} . \%$, solid solutioning would increase the hardness and modulus as presented in Figure 7. However, this simple phase-mixture may not be sufficient in explaining the concentration-dependent hardness presented in Figure 7(b). While a relative minimum in hardness ( 2 GPa) was observed at approximately $6 \mathrm{wt} . \%$ Mo similar to the modulus, a relative maximum ( 6 GPa) was also observed around 2 wt.\% Mo.

Figure 8 presents a bright-field micrograph and the corresponding SAED from the TEM sample with negligible Mo content $(\mathrm{E}=169.3 \pm 12.8 \mathrm{GPa}$ and $\mathrm{H}=5.72 \pm 0.76)$. The pure $\mathrm{U}$ sample was completely $\alpha$, indicating that no $\gamma$-phase was retained upon cooling from the annealing temperature of $1000^{\circ} \mathrm{C}$. On the other hand, the TEM sample with the composition of U-10 wt.\% Mo consisted entirely of $\gamma$-phase, demonstrating that the BCC structure was stabilized completely and no transformation took place upon cooling after diffusion anneal as 
shown by the bright-field micrograph and SAED in Figure 9. The $\gamma$-phase with the composition of U-10 wt.\% Mo had reduced modulus and hardness of approximately $95 \mathrm{GPa}$ and $4 \mathrm{GPa}$, respectively according to Figure 7.

Additional samples having approximate concentrations of approximately $6 \mathrm{wt} . \%$ and 2 wt.\% Mo were prepared for TEM analyses. The sample with 6 wt.\% Mo, according to Figure 7 , corresponds to the composition where relative minima in reduced modulus $(63.3 \pm 3.6 \mathrm{GPa})$ and hardness $(2.29 \pm 0.11 \mathrm{GPa})$ were observed. As shown in Figure 10, TEM analyses demonstrated the presence of only the BCC $\gamma$-phase with additional reflections corresponding to $\{1 / 21 / 21\}$ planes. Similar reflections have been reported as a superlattice structure $\mathrm{U}_{3} \mathrm{Mo}$ [39]. Microstructure of the TEM sample with 2 wt.\% Mo was complex as presented in Figure 11. As seen by both bright- and dark-field micrographs, needle-like features, typical of martensitic transformations were prevalent, which have been observed and documented in the U-Mo system [40-43]. Further investigation is necessary to completely document the phase constitution in the Mo dilute regions (<6 wt.\%) for better understanding of the variation in mechanical behavior assessed by nanoindentation shown in Figure 7.

Aforementioned, the elastic modulus determined as a function of Mo concentration presented in Figure 7 may be mostly attributed to the mixture of phases and variation in compositions within these phases. Figure 12(a) presents a result from a semi-quantitative analysis carried out to understand the influence of phase mixture and solid solutioning on the concentration-dependent Young's modulus observed in this study. The elastic modulus of $\alpha-U$ can be assumed as a constant value of $180 \mathrm{GPa}[22,44]$ due to insignificant Mo solubility, less than 1 at.\% [45]. For the $\gamma$-phase with Mo content less than $6 \mathrm{wt} \%$, mechanical properties are not readily available from experimentation since the $\gamma$-phase is not easily retained at room 
temperature. The lowest elastic modulus for the $\gamma$-phase has been reported as $50.1 \mathrm{GPa}$ at approximately $7 \mathrm{wt} \%$ Mo [36]. This value has been applied as the elastic modulus of $\gamma$-phase with concentration of $6 \mathrm{wt} . \%$ Mo where a minimum modulus value was observed, and TEM analysis revealed a completely retained $\gamma$-phase. The mixture of $\alpha$ and $\gamma$ phases was modeled as presented in Figure 12(b) to "best-fit" the concentration-dependent Young's modulus shown in Figure 12(a) for the concentration less than 6 wt.\% Mo. For concentration higher than 6 wt. $\%$ Mo, an increase in modulus was "best-fit" as shown in Figure 12(a) based on assumption of solid solutioning within the $\gamma$-phase presented in Figure 12(c). While the phase mixture and solidsolutioning may be a simplistic approach to explain the concentration-dependence of hardness shown in Figure 7(b), agreement presented in Figure 12(a) for Young's modulus is close.

Occasionally, inclusions were found in U-10Mo fuel alloys, mostly in the form of uranium carbide (UC) as seen in Figure 2(g). Crystallographic identification, approximate stoichiometry and their influence on the fuel fabrication were previously reported $[13,36,46]$. Figure 13 presents a typical array of indentations performed on inclusions, and Table II reports the hardness $(4.65 \pm 0.05 \mathrm{GPa})$ and reduced modulus $(112.8 \pm 4.7 \mathrm{GPa})$ determined from indentations that were clearly within the carbide phase, indicated by red squares. Fine cellular precipitates in Figure 13, present within yellow circles, are on-set of $\gamma$-to- $\alpha$ phase transformation, and not the inclusion phases. The $\mathrm{UO}_{2}$ phase was present in very small amounts, typically as thin layers within the UC phase [13], as labeled in Figure 13. Young's modulus for the UC is estimated at $114.2 \pm 4.29 \mathrm{GPa}$ which is significantly lower than $243 \mathrm{GPa}$ reported in literature [23,47,48]. The hardness of UC ranged from 650 to $725 \mathrm{VHN}$ [49], corresponding to a range of 6.41 to $7.16 \mathrm{GPa}$, which is also higher than the hardness observed in this study. These 
differences may arise due to stoichiometric deviation and/or geometric limitation (e.g., indentation on thin or shallow oxide/carbide phase) inherent in indentation testing.

\section{Summary and Conclusions}

Hardness and reduced modulus of several intermetallic and solid solution phases relevant to the fabrication process of monolithic fuel plate were investigated by nanoindentation using HIP'ed fuel plates and diffusion couples. A hardness of 11.2 $\pm 1.28 \mathrm{GPa}$ and a reduced modulus of $206.0 \pm 15.4$ were obtained for the $\mathrm{Al}_{3} \mathrm{Zr}$ phase from $\mathrm{Al}$ vs. $\mathrm{Zr}$ diffusion couple annealed at $425^{\circ} \mathrm{C}$ for 720 hours. Reduction in hardness, $11.4 \pm 0.85 \mathrm{GPa}$ and reduced modulus, $173.3 \pm 4.7$

GPa was observed for the $(\mathrm{Al}, \mathrm{Si})_{3} \mathrm{Zr}$ phase in the HIP plate sample from the interaction of $\mathrm{Zr}$ and AA6061 cladding alloy through $\mathrm{HIP}$ at $560^{\circ} \mathrm{C}$ for 3 hours. The $\mathrm{UZr}_{2}, \mathrm{Mo}_{2} \mathrm{Zr}$, and Mo-depleted $\alpha-$ $\mathrm{U}$ developed due to the interdiffusion and reaction between $\mathrm{U}-10 \mathrm{Mo}$ fuel and $\mathrm{Zr}$ diffusion barrier. Hardness of these phases was, in GPa, $5.4 \pm 0.20,13.0 \pm 1.11,4.7 \pm 0.10$, respectively, and reduced modulus of these phases was, in GPa, 126.7 $\pm 1.9,157.7 \pm 9.5,169.0 \pm 3.2$, respectively. The U-Mo solid solution exhibited decreasing reduced modulus from pure U to approximately $6 \mathrm{wt} . \%$ Mo, followed by increasing modulus with increasing Mo content up to 10 wt.\%. This behavior was semi-quantatively modeled by mixture of $\alpha$ - and $\gamma$-phases from pure $U$ to 6 wt.\% Mo, followed by solid solutioning within the $\gamma$-phase from 6 wt. $\%$ to 10 wt.\% Mo. The properties reported for these phases can lead to a better understanding regarding the mechanical behavior of the entire fuel plate and help model the fabrication process and irradiation behavior. 


\section{Acknowledgments}

This work was supported by the U.S. Department of Energy, Office of Nuclear Materials Threat

Reduction (NA-212), National Nuclear Security Administration, under DOE-NE Idaho

Operations Office Contract DE-AC07-05ID14517. Accordingly, the U.S. Government retains a

non-exclusive, royalty-free license to publish or reproduce the published form of this

contribution, or allow others to do so, for U.S. Government purposes.

\section{References}

1. Snelgrove, J. L.; Hofman, G. L.; Meyer, M. K.; Trybus, C. L.; Wiencek, T. C., Nuclear Engineering and Design 1997, 178, 119-126.

2. Angerman, C. L.; Caskey, G. R., Journal of Nuclear Materials 1964, 13 (2), 182-196.

3. Kim, Y. S.; Hofman, G. L., Journal of Nuclear Materials 2011, 419 (1-3), 291-301.

4. Robinson, A. B.; Chang, G. S.; Keiser, Jr., D. D.; Wachs, D. M.; Porter, D. L., Irradiation Performance of U-Mo Alloy Based 'Monolithic' Plate-Type Fuel Design Selection; INL external report INL/EXT-09-16807: Idaho Falls, Iadho 83415, 2009.

5. $\quad$ Meyer, M.; Gan, J.; Jue, J. F.; Keiser, Jr., D. D.; Perez, E.; Robinson, A.; Wachs, D. M.; Woolstenhulme, N.; Hofman, G. L.; Kim, Y. S., Nuclear Engineering and Technology 2014, 46 (2), 169-182.

6. Perez, E.; Yao, B.; Keiser, Jr., D. D.; Sohn, Y. H., Journal of Nuclear Materials 2010, 402, 8-14.

7. Moore, G. A.; Marshall, M. C., Co-Rolled U10Mo/Zirconium-Barrier-Layer Monolithic Fuel Foil Fabrication Process; INL External Report INL/EXT-10-17774: Idaho Falls, Idaho 83415, 2010.

8. Jue, J. F.; Keiser, D. D.; Breckenridge, C. R.; Moore, G. A.; Meyer, M. K., Journal of Nuclear Materials 2014, 448 (1), 250-258.

9. Huang, K.; Park, Y.; Keiser, Jr., D. D.; Sohn, Y. H., Journal of Phase Equilibria and Diffusion 2012, 33, 443-449.

10. Park, Y.; Yoo, J.; Huang, K.; Keiser, Jr., D. D.; Jue, J.F.; Rabin, B.; Moore, G.; Sohn, Y. H., Journal of Nuclear Materials 2014, 447, 215-224.12.

11. Huang, K.; Kammerer, C.; Keiser, Jr., D.D.; Sohn, Y. H., Journal of Phase Equilibria and Diffusion 2014, 35, 146-156.

12. Park, Y.; Keiser, Jr., D. D.; Sohn, Y. H., Journal of Nuclear Materials 2015, 456, 351-358.

13. Park, Y.; Eriksson, N.; Keiser, Jr., D. D.; Jue, J.F.; Rabin, B.; Moore, G.; Sohn, Y. H., Materials Characterization 2015, 103, 50-57. 
14. Oliver, W. C.; Pharr, G. M., Journal of materials research 1992, 7 (06), 1564-1583.

15. Oliver, W. C.; Pharr, G. M., Journal of materials research 2004, 19 (01), 3-20.

16. Moore, G.; Jue, J. F.; Rabin, B.; Nilles, M., Full size U-10Mo monolithic fuel foil and fuel plate fabrication-technology development. In Proceedings of RRFM 2012, Marrakesh, Morroco, 2010.

17. Crapps, J.; Clarke, K.; Katz, J.; Alexander, D. J.; Aikin, B.; Vargas, V. D.; Montalvo, J. D.; Dombrowski, D. E.; Mihaila, B., Nuclear Engineering and Design 2013, 254, 43-52.

18. Huang, K.; Keiser, Jr, D. D.; Sohn, Y.H., Metallurgical and Materials Transactions A 2013, 44 (2), 738-746.

19. Duan, Y. H.; Sun, Y.; Peng, M. J.; Zhou, S. G., Journal of Physics and Chemistry of Solids 2014, 75 (4), 535-542.

20. Li, C. M.; Zeng, S. M.; Chen, Z. Q.; Cheng, N. P.; Chen, T. X., Computational Materials Science 2014, 93, 210-220.

21. Fisher, E. S.; McSkimin, H. J., Journal of Applied Physics 1958, 29 (10), 1473-1484.

22. Waldron, M.; Burnett, R.; Pugh, S., The mechanical properties of Uranium-Molybdenum alloys; United Kingdom Atomic Energy Authority. Research Group. Atomic Energy Research Establishment, Harwell, Berks, England: 1958.

23. Mullen, R. L.; Ballarini, R.; Yin, Y.; Heuer, A. H., Acta Materialia 1997, 45 (6), 22472255.

24. Fu, L.; Ke, J. L.; Zhang, Q.; Tang, B. Y.; Peng, L. M.; Ding, W. J., Physica Status Solidi (b) 2012, 249 (8), 1510-1516.

25. Gudla, V. C.; Rechendorff, K.; Balogh, Z. I.; Kasama, T.; Ambat, R., Materials and Design 2016, 89, 1071-1078.

26. Knipling, K. E.; Seidman, D. N.; Dunand, D. C., Acta Materialia 2011, 59 (3), 943-954.

27. Clouet, E.; Sanchez, J. M.; Sigli, C., Physical Review B 2002, 65 (9), 094105.

28. Virk, I. S.; Varin, R. A., Metallurgical Transactions A 1992, 23 (2), 617-625.

29. Sheldon, R. I.; Peterson, D. E., Bulletin of Alloy Phase Diagrams 1989, 10 (2), 165-171.

30. Basak, C. B.; Prabhu, N.; Krishnan, M., Intermetallics 2010, 18 (9), 1707-1712.

31. Akabori, M.; Ogawa, T.; Itoh, A.; Morii, Y., Journal of Physics-Condensed Matter 1995, 7 (43), 8249-8257.

32. Zinkevich, M.; Mattern, N., Journal of phase equilibria 2002, 23 (2), 156-162.

33. Beeler, B.; Deo, C.; Baskes, M.; Okuniewski, M., Journal of Nuclear Materials 2013, 433 (1-3), 143-151.

34. Vlassak, J. J.; Nix, W. D., Journal of the Mechanics and Physics of Solids 1994, 42 (8), 1223-1245.

35. Chen, X.; Yan, J.; Karlsson, A. M., Materials Science and Engineering: A 2006, 416 (1-2), 139-149.

36. Burkes, D. E.; Prabhakaran, R.; Hartmann, T.; Jue, J. F.; Rice, F. J., Nuclear Engineering and Design 2010, 240 (6), 1332-1339.

37. Burkes, D. E.; Hartmann, T.; Prabhakaran, R.; Jue, J. F., Journal of Alloys and Compounds 2009, 479 (1-2), 140-147. 
38. Yovanovich, M. In Micro and macro hardness measurements, correlations, and contact models, Collection of technical papers - 44th AIAA aerospace sciences meeting, 2006; pp $11702-11729$.

39. Seong, B. S.; Lee, C. H.; Lee, J. S.; Shim, H. S.; Lee, J. H.; Kim, K. H.; Kim, C. K.; Em, V., Journal of Nuclear Materials 2000, 277 (2-3), 274-279.

40. Orlov, V.; Teplinskaya, V., Atomic Energy 1999, 86 (2), 118-125.

41. Orlov, V.; Teplinskaya, V.; Chebotarev, N., Atomic Energy 2000, 88 (1), $42-47$.

42. Tangri, K.; Williams, G., Journal of Nuclear Materials 1961, 4 (2), 226-233.

43. Howlett, B., Journal of Nuclear Materials 1970, 35 (3), 278-292.

44. Olofson, C. T.; Meyer, G. E.; Hoffmanner, A. L. Processing and applications of depleted uranium alloy products; DTIC Document: 1976.

45. Sinha, V.; Hegde, P.; Prasad, G.; Dey, G.; Kamath, H., Journal of Alloys and Compounds 2010, 491 (1), 753-760.

46. Nomine, A.; Bedere, D.; Miannay, D.; Burke, J.; Colling, D.; Gorum, A.; Greenspan, J., Physical Metallurgy of Uranium Alloys: Third Army Materials Technology Conference. Brook Hill Publishing Company, Vail, Colorado: 1974.

47. Padel, A.; De Novion, C., Elastic Constants of the Carbides, Nitrides, and Oxides of Uranium and Plutonium; Secper, Fontenay-aux-Roses, France: 1969.

48. Martienssen, W.; Warlimont, H., Springer handbook of condensed matter and materials data. Springer Science \& Business Media: 2006.

49. Smith, C.; Rough, F., Nuclear Science and Engineering 1959, 6 (5), 391-395. 
Table I. Relevant phases and the corresponding samples examined in this study.

\begin{tabular}{|c|c|c|c|}
\hline Phases & Sample type & Description & References \\
\hline$(\mathrm{Al}, \mathrm{Si})_{3} \mathrm{Zr}$ & HIP fuel plate & HIP'ed at $560^{\circ} \mathrm{C}$ for 3 hours & {$[10]$} \\
\hline $\mathrm{Al}_{3} \mathrm{Zr}$ & Diffusion couple & $\begin{array}{l}\text { Al vs. } \mathrm{Zr} \text { annealed at } 425^{\circ} \mathrm{C} \text { for } 720 \\
\text { hours }\end{array}$ & This study \\
\hline $\mathrm{UZr}_{2}$ & Diffusion couple & $\begin{array}{l}\mathrm{U} \text { vs. } \mathrm{Zr} \text { annealed at } 580^{\circ} \mathrm{C} \text { for } 360 \\
\text { hours }\end{array}$ & This study \\
\hline $\mathrm{Mo}_{2} \mathrm{Zr}$ & Diffusion couple & $\begin{array}{l}\mathrm{U}-10 \mathrm{Mo} \text { vs. } \mathrm{Zr} \text { annealed at } 800^{\circ} \mathrm{C} \text { for } \\
480 \text { hours }\end{array}$ & {$[9]$} \\
\hline$\alpha-U$ & Diffusion couple & $\begin{array}{l}\mathrm{U} \text { vs. } \mathrm{Zr} \text { annealed at } 580^{\circ} \mathrm{C} \text { for } 360 \\
\text { hours }\end{array}$ & This study \\
\hline$\gamma$-U(Mo) & Diffusion couple & $\begin{array}{l}\mathrm{U} \text { vs. Mo annealed at } 1000^{\circ} \mathrm{C} \text { for } 24 \\
\text { hours }\end{array}$ & {$[18]$} \\
\hline$\gamma-\mathrm{U}(\mathrm{Mo})$ & Diffusion couple & $\begin{array}{l}\text { U vs. U-10Mo annealed at } 1000^{\circ} \mathrm{C} \text { for } \\
96 \text { hours }\end{array}$ & This study \\
\hline $\mathrm{UC}$ & HIP fuel plate & HIP'ed at $560^{\circ} \mathrm{C}$ for 3 hours & {$[10,13]$} \\
\hline
\end{tabular}

Table II. Hardness, reduced modulus and estimated Young's modulus for various phases examined in this study.

\begin{tabular}{|c|c|c|c|c|c|c|c|}
\hline Phase & $\begin{array}{c}\text { Number } \\
\text { of Indents }\end{array}$ & $\begin{array}{c}\text { Hardness } \\
\text { (GPa) }\end{array}$ & $\begin{array}{c}\text { Reduced } \\
\text { modulus } \\
(\text { GPa })\end{array}$ & $\begin{array}{c}\text { Poisson } \\
\text { ratio }\end{array}$ & $\begin{array}{c}\text { Young's } \\
\text { modulus } \\
(\text { GPa })\end{array}$ & $\begin{array}{c}\text { Young's } \\
\text { modulus from } \\
\text { literature } \\
(\mathbf{G P a})\end{array}$ & $\begin{array}{l}\text { Elastic } \\
\text { properties } \\
\text { reference }\end{array}$ \\
\hline$(\mathrm{Al}, \mathrm{Si})_{3} \mathrm{Zr}$ & 20 & $11.4 \pm 0.85$ & $173.3 \pm 4.71$ & 0.3 & $183.6 \pm 4.30$ & - & Assumed \\
\hline $\mathrm{Al}_{3} \mathrm{Zr}$ & 80 & $11.2 \pm 1.28$ & $206.0 \pm 15.4$ & 0.18 & $239.6 \pm 15.1$ & $201.8 \sim 210.6$ & {$[19]^{@}[20]^{@}$} \\
\hline $\mathrm{UZr}_{2}$ & 65 & $5.4 \pm 0.20$ & $126.7 \pm 1.9$ & 0.3 & $128.6 \pm 1.73$ & - & Assumed \\
\hline $\mathrm{Mo}_{2} \mathrm{Zr}$ & 15 & $13.0 \pm 1.11$ & $157.7 \pm 9.5$ & 0.3 & $164.7 \pm 8.71$ & - & Assumed \\
\hline$\alpha-U$ & 90 & $4.7 \pm 0.10$ & $169.0 \pm 3.2$ & 0.21 & $187.4 \pm 3.07$ & 208 & {$[21]^{\#}$} \\
\hline $\begin{array}{c}\gamma \text {-U(Mo) } \\
\text { Solid } \\
\text { Solution }\end{array}$ & 1000 & $\begin{array}{c}2.29 \pm 0.11 \sim \\
4.42 \pm 0.21\end{array}$ & $\begin{array}{l}63.3 \pm 3.6 \sim \\
104.6 \pm 3.08\end{array}$ & 0.35 & $\begin{array}{c}58.6 \pm 3.17 \sim \\
97.0 \pm 3.12\end{array}$ & $50.1 \sim 94.7$ & {$[22]^{\$}$} \\
\hline UC & 12 & $4.65 \pm 0.05$ & $112.8 \pm 4.7$ & 0.284 & $114.2 \pm 4.29$ & 243 & {$[23]^{\%}$} \\
\hline
\end{tabular}

${ }^{\circledR}$ First principle calculation; ${ }^{\#}$ Ultrasonic wave; ${ }^{\$}$ tensile testing; ${ }^{\%}$ Monte Carlo simulation 


\section{List of Figures}

1. Representative microstructure of monolithic U-10Mo fuel plate [10].

2. Microstructure of (a) $(\mathrm{Al}, \mathrm{Si})_{3} \mathrm{Zr}$, (b) $\mathrm{Al}_{3} \mathrm{Zr}$, (c) $\mathrm{UZr}_{2}$, (d) $\mathrm{Mo}_{2} \mathrm{Zr}$, (e) $\gamma$-phase U-10Mo solid solution, (f) $\alpha-\mathrm{U}$ and $\gamma$-U10Mo solid solution, (g) UC phases, observed within the HIP fuel plate sample and diffusion couples examined for nanoindentation.

3. Indentation array performed on HIP plate sample 56-180, highlighting the indentations that yielded the hardness and reduced modulus for the $(\mathrm{Al}, \mathrm{Si})_{3} \mathrm{Zr}$ phase with red dotted circles.

4. Indentation array performed on $\mathrm{Al}_{3} \mathrm{Zr}$ phase developed in $\mathrm{Al}$ vs. $\mathrm{Zr}$ diffusion couple annealed at $425^{\circ} \mathrm{C}$ for 720 hours.

5. Indentation array performed on $\mathrm{UZr}_{2}$ and $\alpha-\mathrm{U}$ developed on $\mathrm{U}$ vs. $\mathrm{Zr}$ diffusion couple annealed at $580^{\circ} \mathrm{C}$ for 360 hours.

6. Indentation array performed on U10Mo vs. $\mathrm{Zr}$ diffusion couple, annealed at $800^{\circ} \mathrm{C}$ for 480 hours. The red circles indicate data points that are clearly within the $\mathrm{Mo}_{2} \mathrm{Zr}$ phase.

7. (a) Elastic modulus and (b) hardness of uranium solid solution as a function of Mo concentration in $\mathrm{U}$ vs. $\mathrm{U}-10 \mathrm{Mo}$ diffusion couple annealed at $1000^{\circ} \mathrm{C}$ for 24 hours.

8. (a) Bright field micrograph and (b) the corresponding SAED pattern from pure U, exhibiting the orthorhombic structure characteristic of $\alpha$-uranium.

9. (a) Bright field micrograph and (b) the corresponding SAED pattern from the U-10Mo sample, exhibiting the $\mathrm{BCC}$ structure characteristic of $\gamma$-uranium.

10. (a) Bright field micrograph and (b) the corresponding SAED pattern from the U-5.4 wt.\% Mo sample, exhibiting the BCC structure characteristic of $\gamma$-uranium with additional reflections corresponding to $\{1 / 21 / 21\}$ planes.

11. (a) Bright-field and (b) dark-field micrographs from the sample with the approximate composition of U-2.0 wt.\% Mo.

12. (a) Calculated Mo concentration-dependent reduced modulus based on (a) mixture of $\alpha$ - and $\gamma$ phases and (b) solid solutioning within the $\gamma$-phase.

13. Indentations on U-10Mo fuel in monolithic fuel plate (HIP processed at $560^{\circ} \mathrm{C}$ for 180 minutes), including near decomposed regions and on UC inclusion. The red dotted squares indicate indents on the UC phase, the blue diamonds on the $\gamma$-phase, and the yellow circles on a mixture of $\gamma$ and decomposed $\alpha$ and $\gamma^{\prime}$ phases. 
AA6061 Cladding

\section{Zr Diffusion Barrier}

\section{U10Mo Fuel}

$100 \mu \mathrm{m}$ 
(a)

$\alpha-u$
(c)

(e)

\section{$\mathrm{V}-\mathrm{U}$}

\section{$\mathrm{UZr}_{2}$}

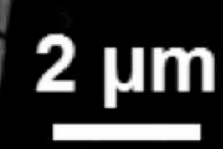

\section{Mo}

$1 \mu \mathrm{m}$

(b)
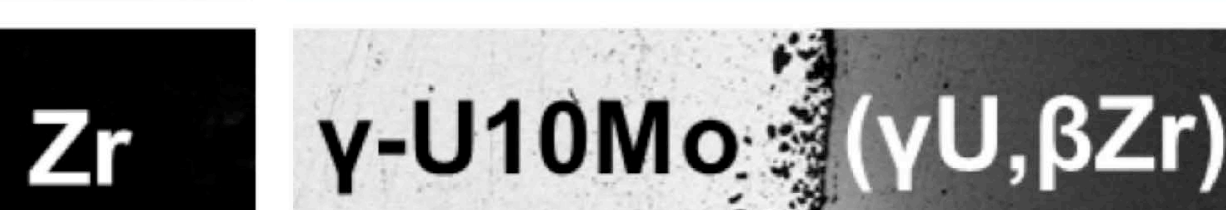

$\mathrm{Zr}$

\section{(d)}

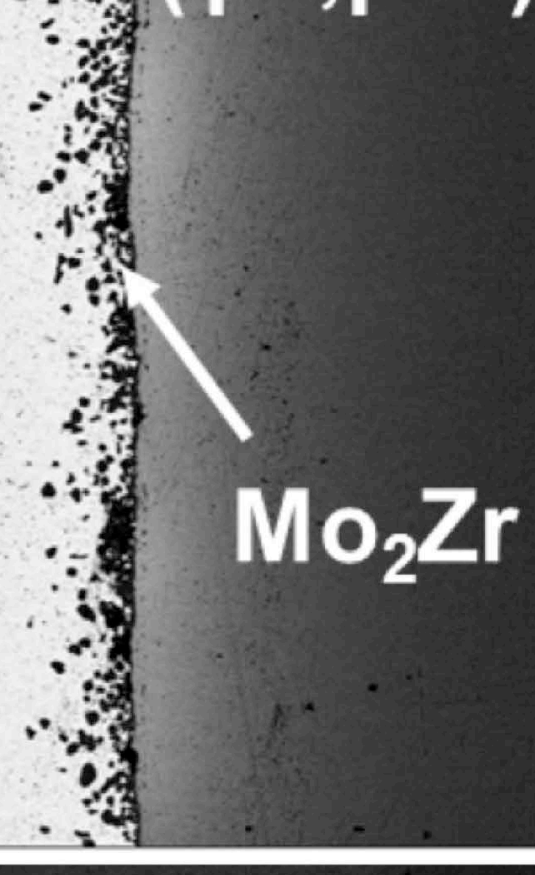

\section{$\alpha-U$}

y-U10Mo

10pm 100pm
Decomposed $\alpha+\mathrm{Mo}_{2} \mathrm{Zr}$ at grain boundaries 
AA6061

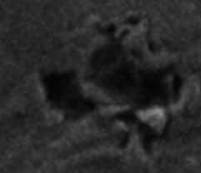

$(\mathrm{Al}, \mathrm{Si})_{3} \mathrm{Zr}$

Zr

$2 \mu \mathrm{m}$ The 


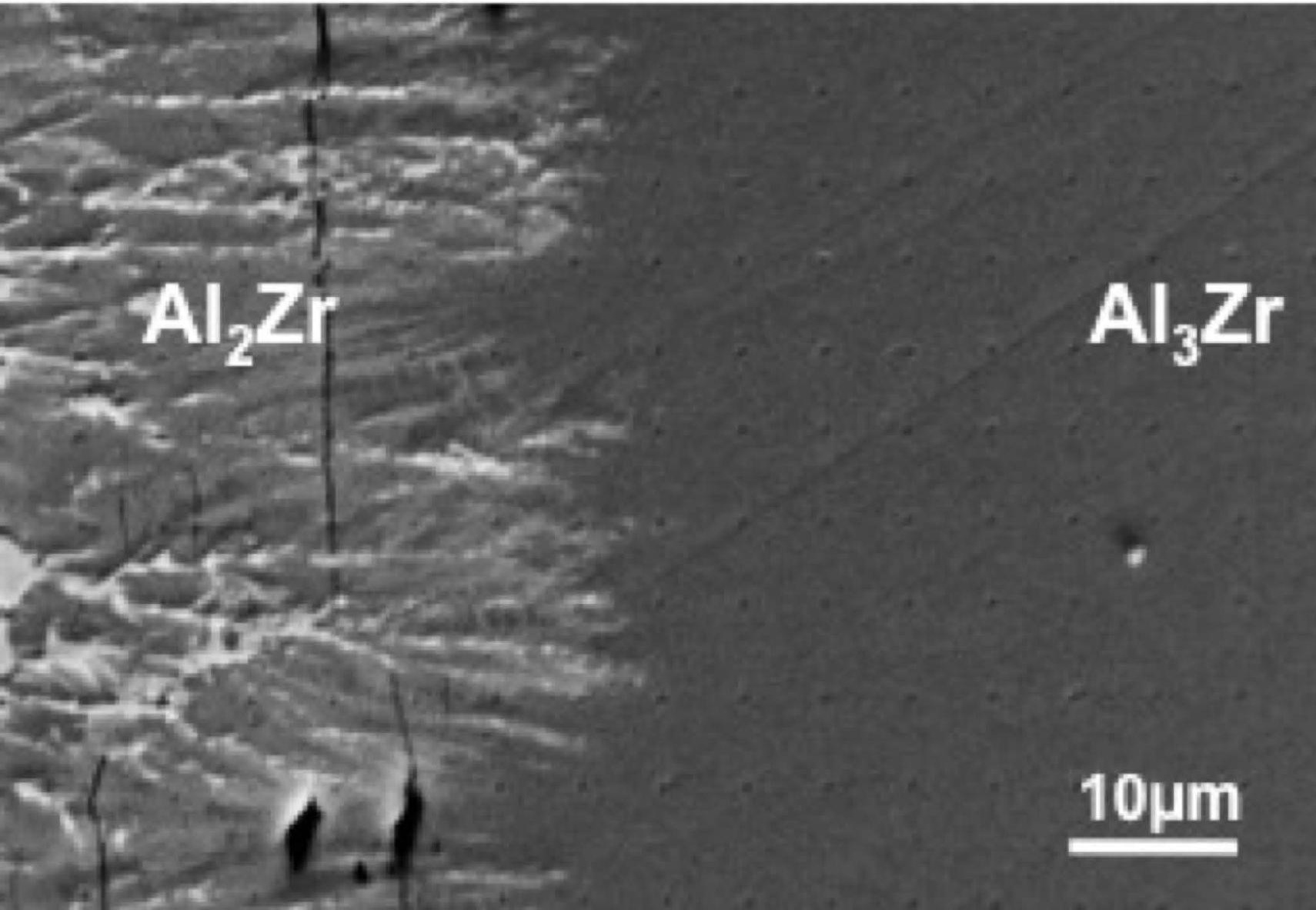


$\alpha-U_{\text {. }}$

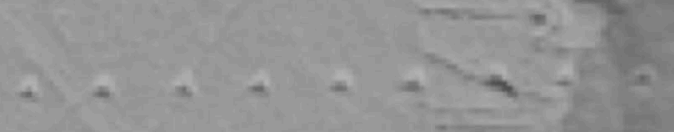

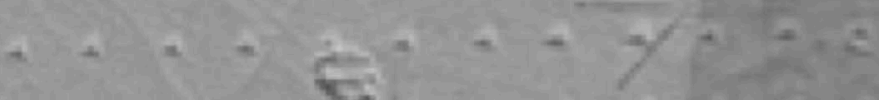

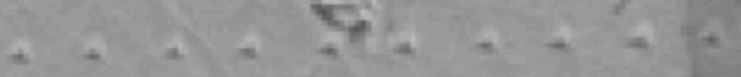

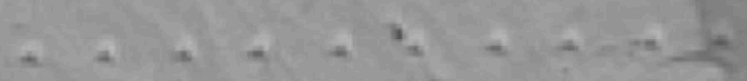

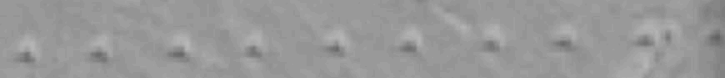

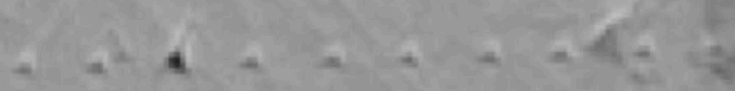

$+4+4+4+4+4=$

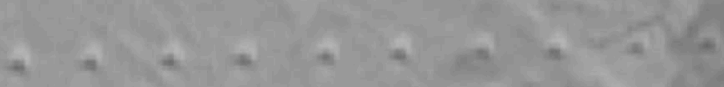

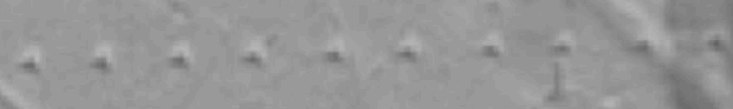

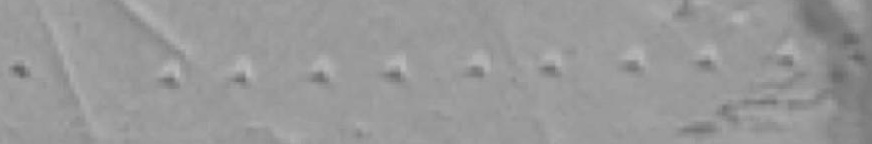




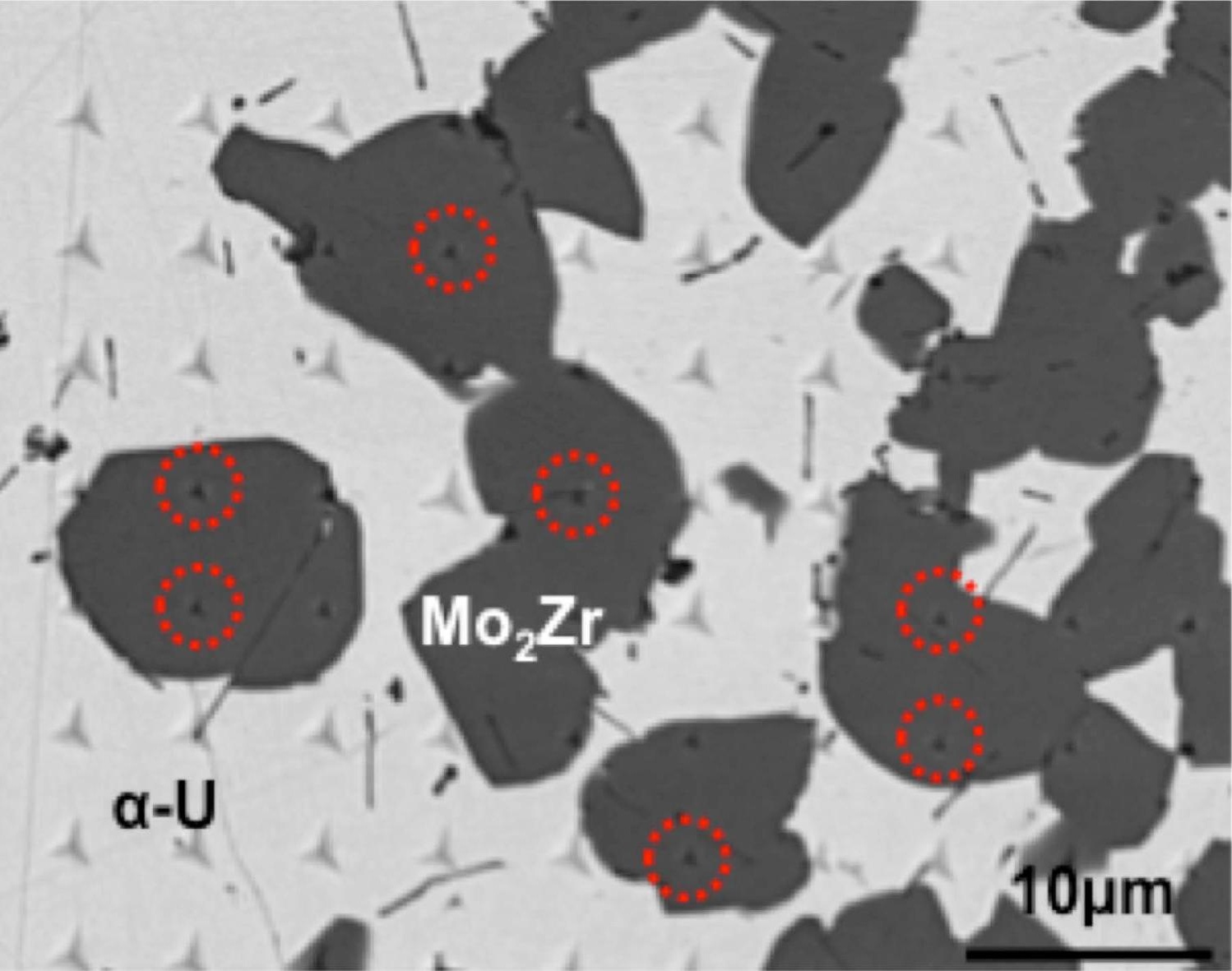


Mo Concentration (Weight \%)

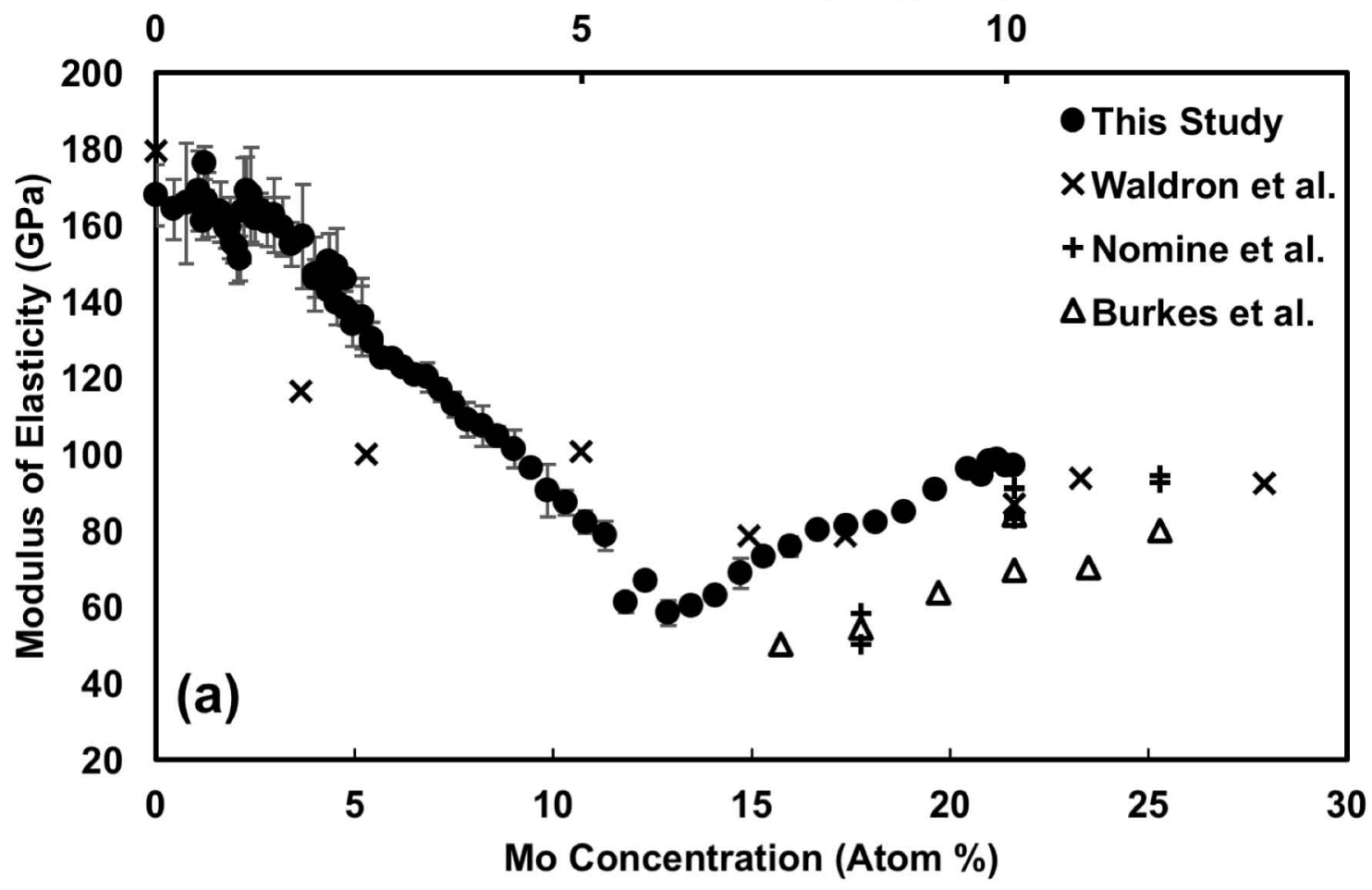

Mo Concentration (Weight \%)

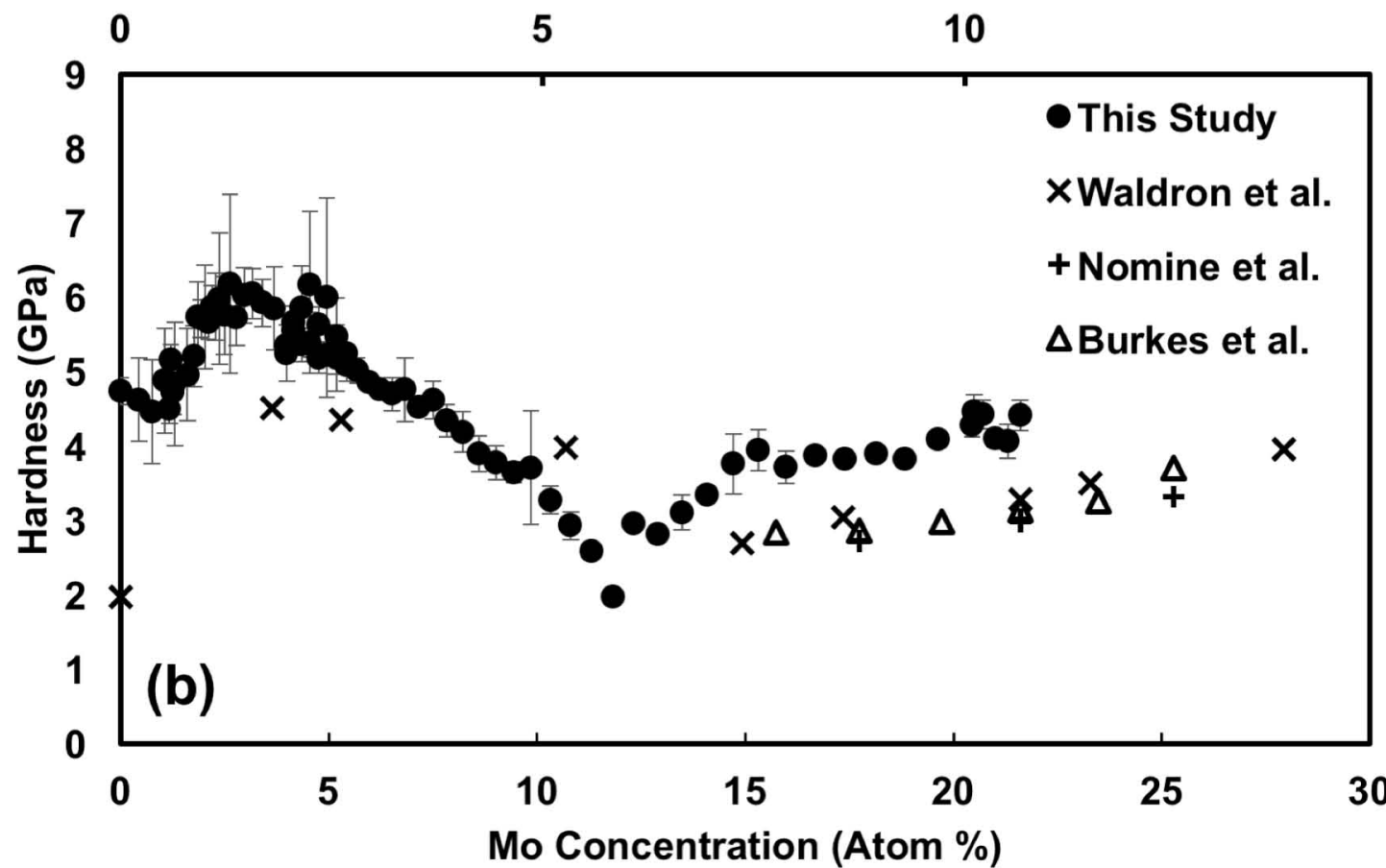




\section{(a)}

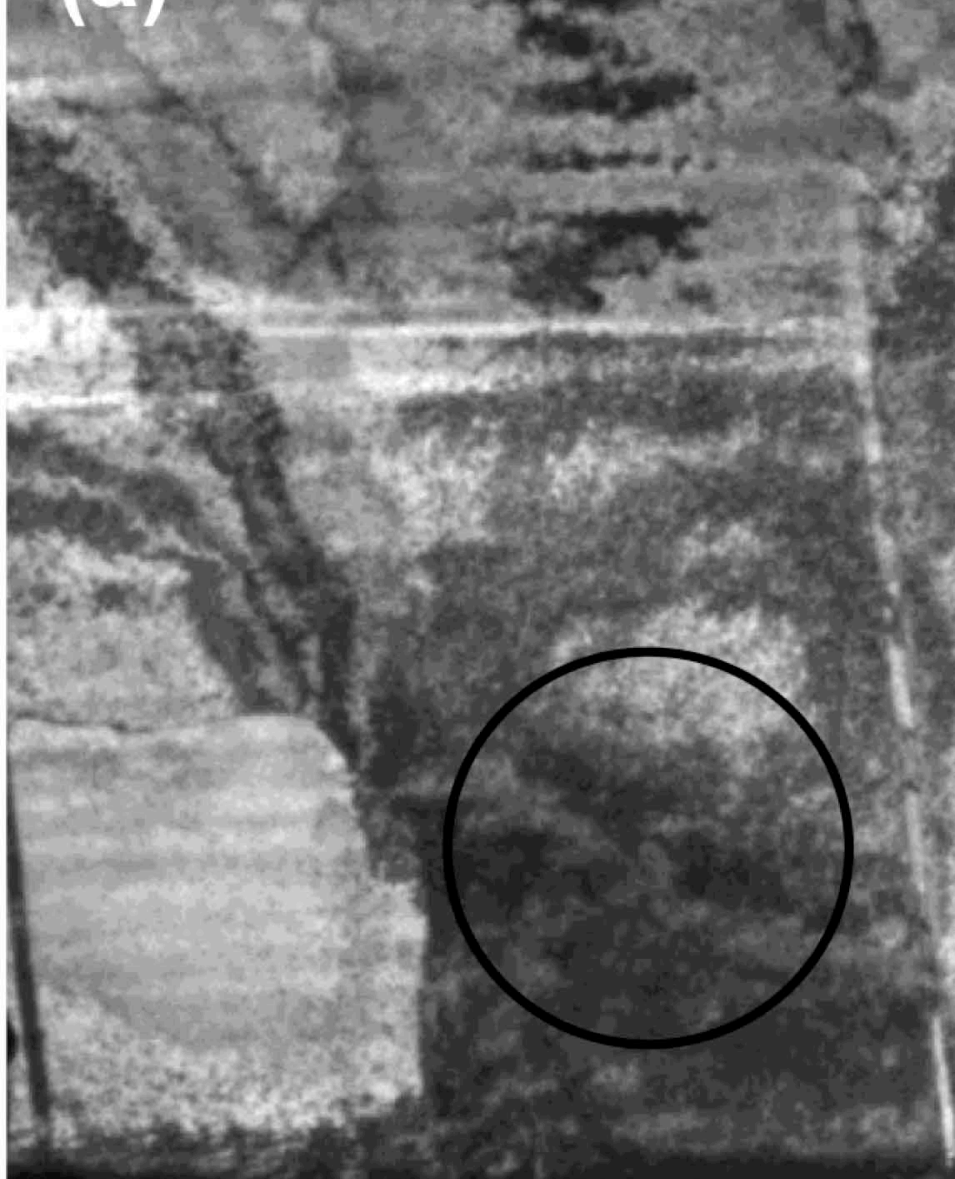

$0.2 \mu \mathrm{m}$

(b)

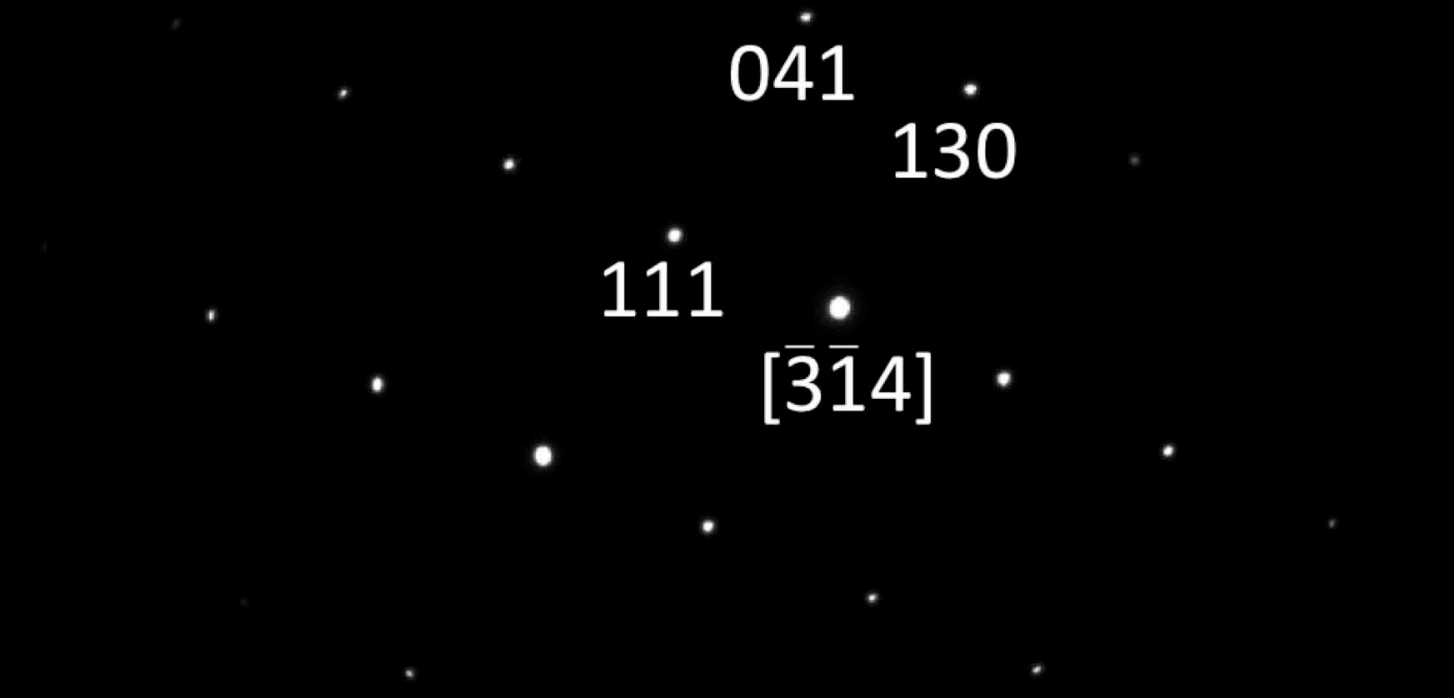

10 1/nm 
(a)

\section{$0.1 \mu \mathrm{m}$}

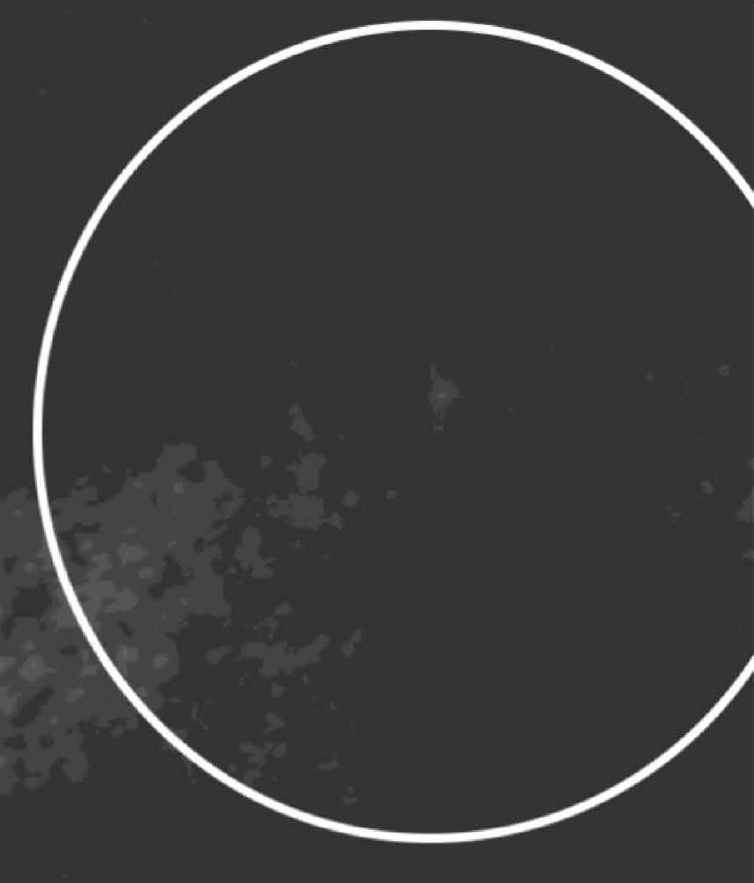

(b)

$\gamma-U$

$101 / \mathrm{nm}$

$1 \dot{21}$

$200^{\circ} \quad \overline{121}$.

[0ั்̋1] . 


\section{$200 \mathrm{~nm}$}

(b)

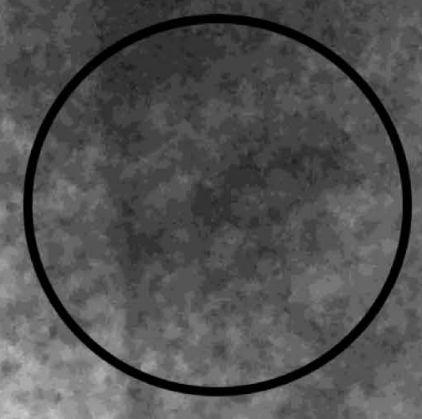

- $211^{\circ} 30^{\circ}$

$*$

9.

- $\left.\quad \stackrel{11 / 2 \frac{1}{2}}{[13 \overline{3} 1]}\right]^{\circ}$

$101 / \mathrm{nm}$ 


\section{(a) $\quad: 8$}

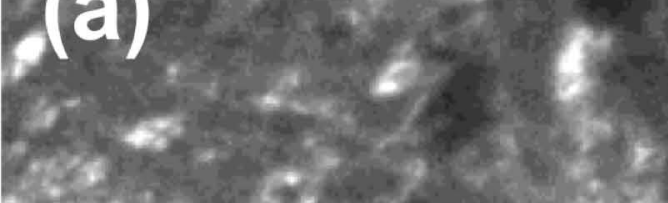

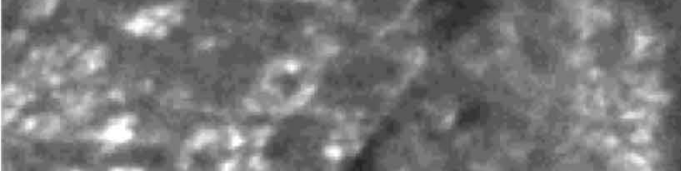

$x=7,2.3 \times 13$

if $=2 \times$

$2+2 x+2=3 x^{2} \times$

$5+2 \times x=3$

$-3+3 y+2=$

$2 x^{2}+3(-3)=$

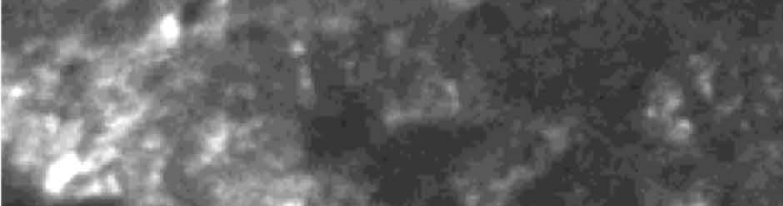

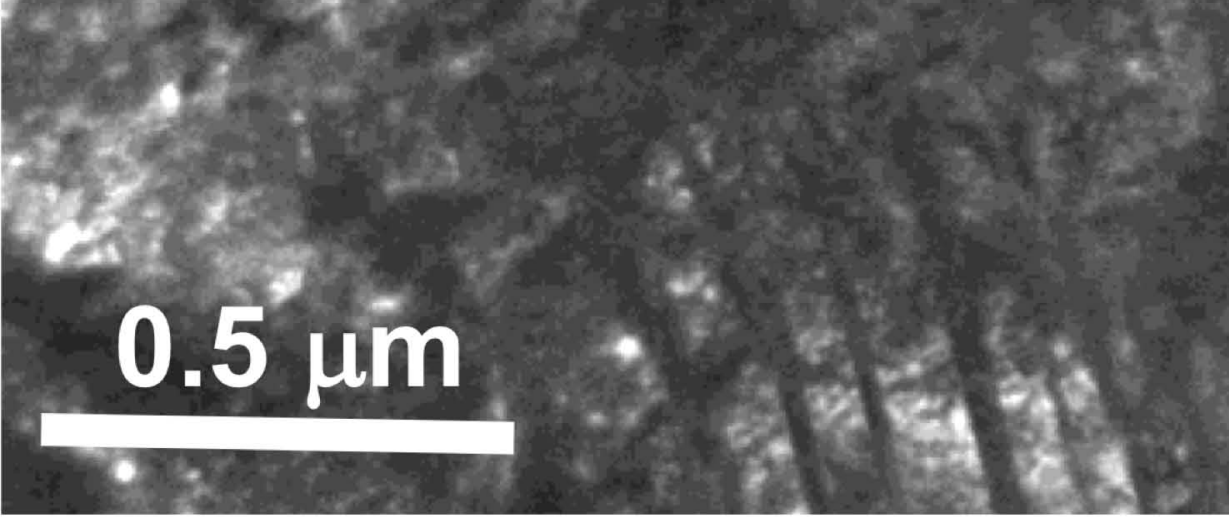

(b) $+2,8$

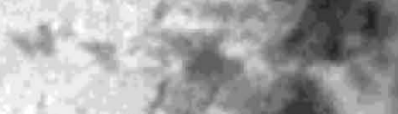

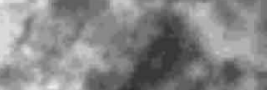

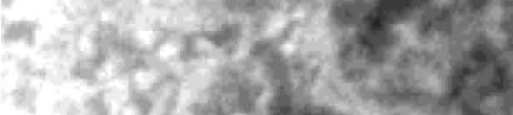

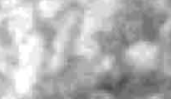

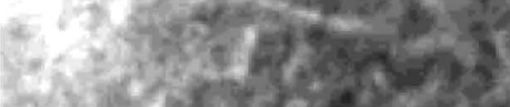

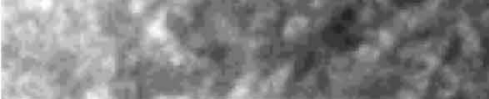

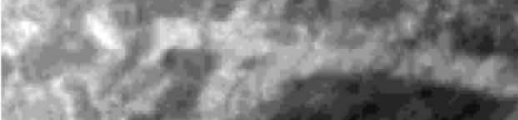

$20 y^{2}=2+21$

$6 x^{2}+2+3$

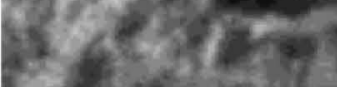


Mo Concentration (Weight \%)

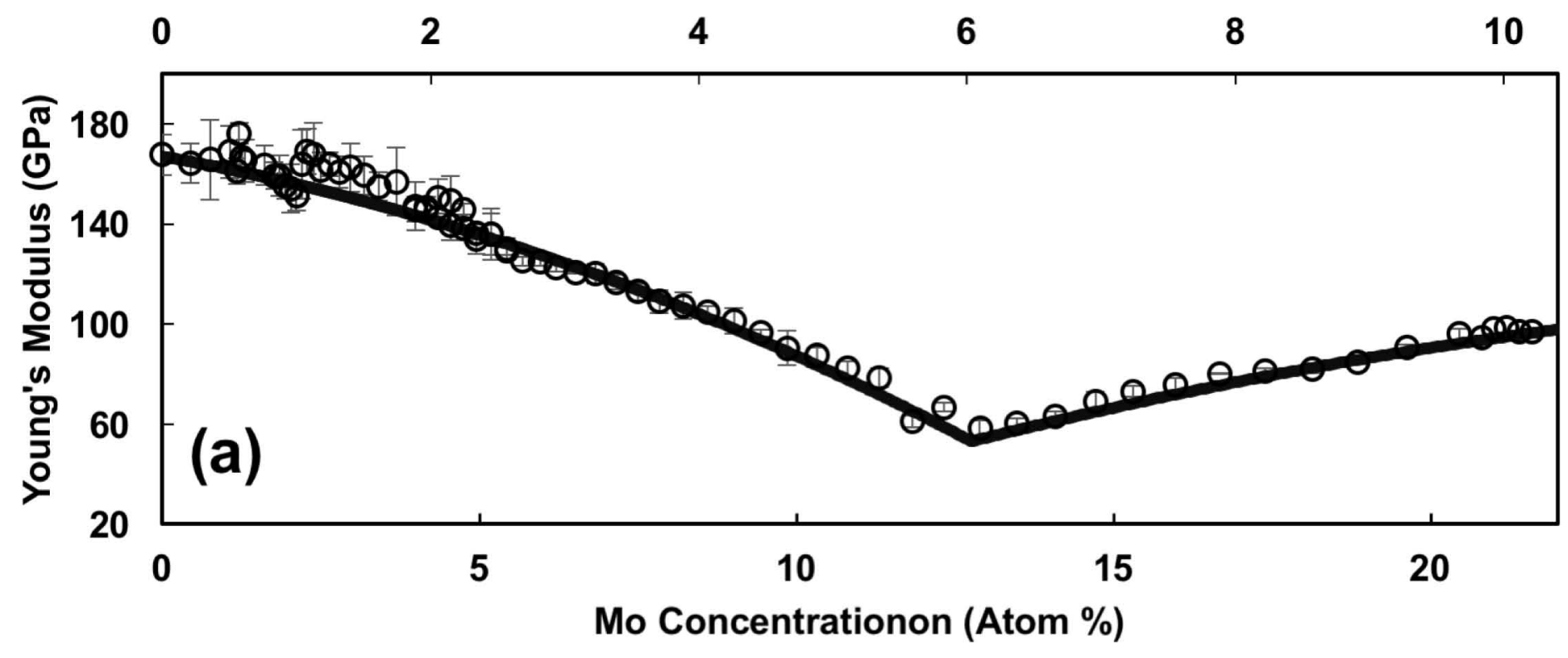

Mo Concentration (Weight \%)

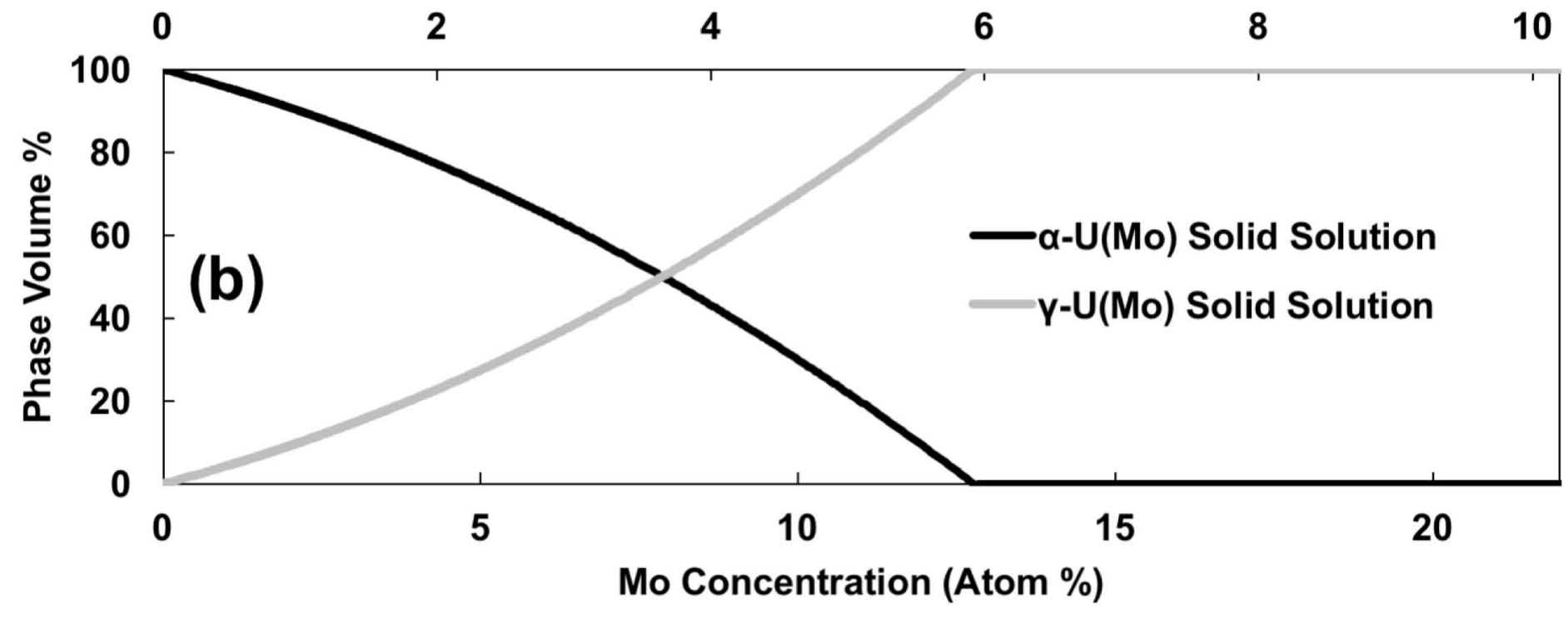

Mo Concentration (Weight \%)

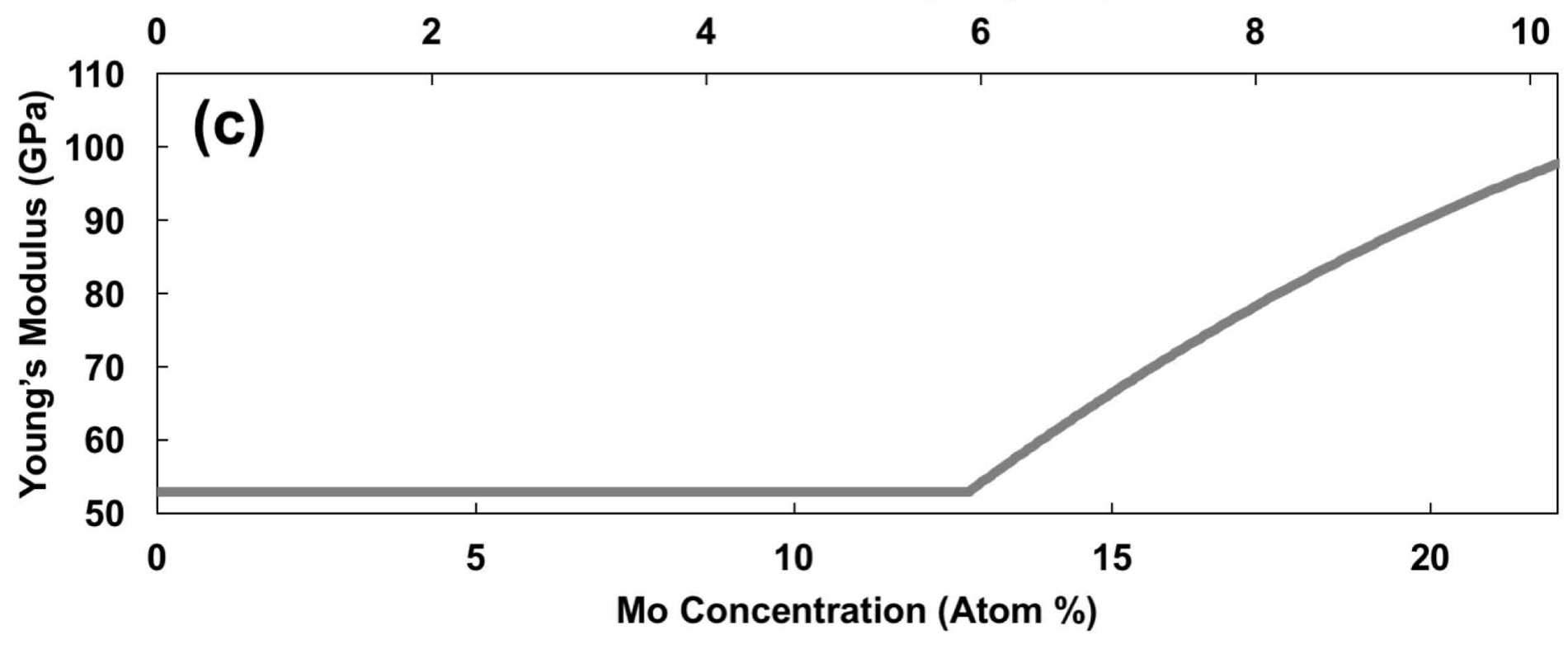




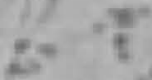

(4) $+\cdots$



6

6

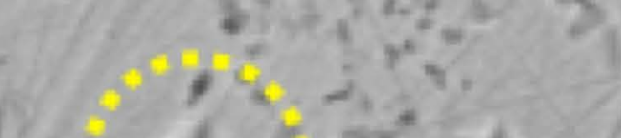

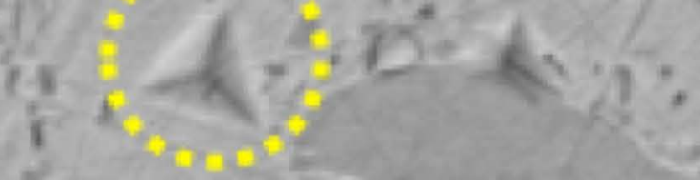

tivis

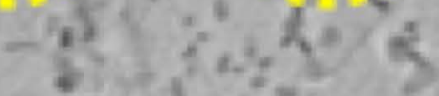

t

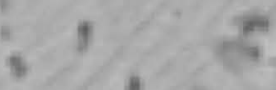

I)

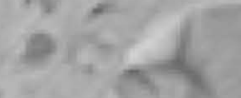

a)

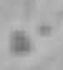

- 8

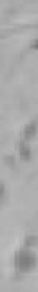

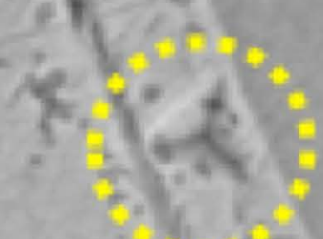

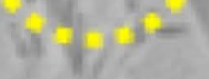

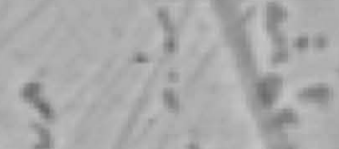

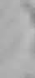<smiles>[CH]=[CH]</smiles>

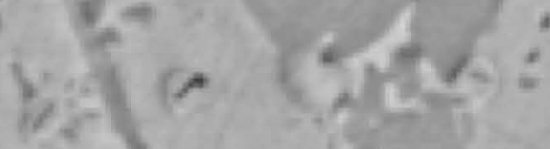
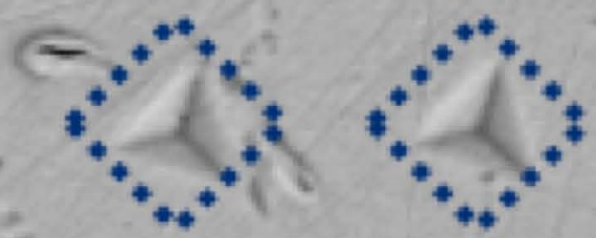